Check for updates

Cite this: Chem. Sci., 2019, 10, 10531

๑ All publication charges for this article have been paid for by the Royal Society of Chemistry

Received 24th June 2019

Accepted 24th September 2019

DOI: $10.1039 / \mathrm{c} 9 \mathrm{sc} 03119 \mathrm{~g}$

rsc.li/chemical-science

\title{
Modulating the surface defects of titanium oxides and consequent reactivity of $\mathrm{Pt}$ catalysts $\uparrow$
}

\author{
Yanan Wang,,$^{\mathrm{a}}$ Sihang Liu, $\dot{t}^{\mathrm{a}}$ Chunlei Pei, ${ }^{\mathrm{a}}$ Qiang Fu, (D) ${ }^{\mathrm{b}}$ Zhi-Jian Zhao, ${ }^{a}$ Rentao $\mathrm{Mu}^{\star a}$ \\ and Jinlong Gong (D) *a
}

In heterogeneous catalysis, it is widely believed that the surface states of catalyst supports can strongly influence the catalytic performance, because active components are generally anchored on supports. This paper describes a detailed understanding of the influence of surface defects of $\mathrm{TiO}_{2}$ supports on the catalytic properties of Pt catalysts. Pt was deposited on reduced ( $\mathrm{r}-$ ), hydroxylated (h-), and oxidized (o-) $\mathrm{TiO}_{2}$ surfaces, respectively, and the different surface states of $\mathrm{TiO}_{2}$ not only lead to differences in metal dispersion, but also distinct electronic interactions between the metal and the support. The highest reactivity for catalytic $\mathrm{CO}$ oxidation can be achieved over the Pt catalyst supported on reduced $\mathrm{TiO}_{2}$ with surface oxygen vacancies. The turnover frequency (TOF) of this catalyst is determined to be $\sim 11$ times higher than that of $\mathrm{Pt}$ supported on oxidized $\mathrm{TiO}_{2}$. More importantly, the reactivity is seen to increase in the sequence of $\mathrm{Pt} / \mathrm{O}-\mathrm{TiO}_{2}<\mathrm{Pt} / \mathrm{h}-\mathrm{TiO}_{2}<\mathrm{Pt} / \mathrm{r}-\mathrm{TiO}_{2}$, which is well consistent with the trend of the calculated Bader charge of Pt.

\section{Introduction}

It has long been recognized that supports play an important role in heterogeneous catalysis, because supports can promote the catalytic performance and reduce the usage of noble metal catalysts..$^{1-5}$ Understanding the interfacial interaction between metals and supports, studied here, is of critical importance as metal-support interactions help the dispersion of active components and sintering resistance. Additionally, a support has also been proposed as a promoter to cause changes in the electronic structure of active components and thereby alter their catalytic properties. As such, a detailed understanding of metal interactions with supports is of high importance. Previously, extensive studies showed that metal nanoparticles and single atom catalysts exhibit variable catalytic reactivity when they are deposited on different supports, such as $\mathrm{SiO}_{2}, \mathrm{Al}_{2} \mathrm{O}_{3}$, $\mathrm{CeO}_{2}, \mathrm{TiO}_{2}, \mathrm{FeO}_{x}$ and many others. ${ }^{6-12}$ Surprisingly, the influence of different surface states of oxide supports on the structure and catalytic performance of metal catalysts has only been studied using model surface science systems while little is known about this factor in real supported catalysts. ${ }^{13-16}$

\footnotetext{
${ }^{a}$ Key Laboratory for Green Chemical Technology of Ministry of Education, School of Chemical Engineering and Technology, Tianjin University; Collaborative Innovation Center of Chemical Science and Engineering (Tianjin), Tianjin 300072, China. E-mail: jlgong@tju.edu.cn; murt@tju.edu.cn

${ }^{b}$ State Key Laboratory of Catalysis, iChEM, Dalian Institute of Chemical Physics, Chinese Academy of Sciences, Dalian 116023, China

$\dagger$ Electronic supplementary information (ESI) available: Experimental and theoretical details, supporting figures and tables. See DOI: $10.1039 / \mathrm{c} 9 \mathrm{sc} 03119 \mathrm{~g}$ $\$$ These authors contributed equally to this work.
}

Recently, several related studies on this issue have been published. Jia and Si et al. discovered that the surface states of iron oxide supports, hydroxylated or dehydrated, play an important role in the performance of $\mathrm{Au} / \mathrm{FeO}_{x}$ in $\mathrm{CO}$ oxidation. ${ }^{17}$ Similarly, Wang et al. compared the performance of Au single atoms on perfect and defective $\mathrm{TiO}_{2}$ nanosheet supports, in which the defective one shows a better performance in $\mathrm{CO}$ oxidation for a lower energy barrier and weaker competitive adsorption. ${ }^{18}$ Furthermore, the study of Christopher et al. provides a detailed understanding of the structure-performance relationship of atomically dispersed catalysts. ${ }^{19,20}$ They show that not only the intrinsic properties of metal atoms, but also the local coordination environment plays a pivotal role in the performance of catalysts.

Surface defects are ubiquitous in many materials and can affect their physical and chemical properties significantly. For example, Xie et al. showed that the $\mathrm{Zn}$ vacancies of $\mathrm{ZnIn}_{2} \mathrm{~S}_{4}$ mediate the electron-hole separation efficiency and boost the reactivity of $\mathrm{CO}_{2}$ reduction. ${ }^{21}$ Surface science studies have shown that the surface defects of supports will affect the binding strength of metal atoms on them. For example, Thornton et al. recently unraveled the binding sites of Au atoms on a reduced $\mathrm{TiO}_{2}$ (110) substrate, and found that bridging oxygen vacancies are the preferential anchoring sites for $\mathrm{Au}$ atoms. ${ }^{22}$ Nevertheless, Buratto et al. discovered that the $\mathrm{Au}$ atoms on oxygen vacancies can be easily replaced by water molecules. ${ }^{23}$ Besenbacher et al. demonstrated that oxygen adatoms bind metal atoms stronger than oxygen vacancies. ${ }^{13-15}$

As one of the most frequently used supports in heterogeneous catalysis, reducible oxides show a diversity of point 
defects at surfaces, such as oxygen vacancies, hydroxyls, oxygen adatoms, etc. It has been demonstrated that these defects are fragile, environmentally sensitive and facile to transform from one to another. For example, the oxygen vacancies at the surface of many oxides can interact with water molecules and easily break them into two hydroxyl groups. ${ }^{24-28}$ Upon annealing treatment in a vacuum or a reductive atmosphere, hydroxyls will recombine into water again, forming a reduced surface with oxygen vacancies. ${ }^{29}$ Consequently, direct studies of the influence of a specific kind of surface defect on the catalytic reactivity remain a great challenge, in particular for catalysts supported on oxide nanoparticles.

This paper focuses on the influence of different surface defects of $\mathrm{TiO}_{2}$ supports on the catalytic properties of $\mathrm{Pt}$ catalysts, because $\mathrm{Pt} / \mathrm{TiO}_{2}$ has been extensively used in heterogeneous catalysis, photocatalytic water splitting, and electrochemistry. ${ }^{30-34}$ By finely tuning the surface states of $\mathrm{TiO}_{2}$, we prepare $\mathrm{Pt}$ catalysts deposited on reduced (r-), hydroxylated (h-) and oxidized (o-) surfaces, respectively. It is shown that the surface states of $\mathrm{TiO}_{2}$ not only influence the degree of metal dispersion, but also change the electronic metal-support interactions which affect the catalytic properties of Pt directly.

\section{Results and discussion}

\section{Modulating the surface states of $\mathrm{TiO}_{2}$ supports}

$\mathrm{TiO}_{2}$ supports with different surface states were prepared in a specific atmosphere. The detailed preparation process is given in Fig. S1. $\dagger$ First, commercial rutile $\mathrm{TiO}_{2}$ was calcined in $\mathrm{Ar}$ and $\mathrm{O}_{2}$ to remove contaminants, such as carbonate and moisture. To prepare a reduced surface, $\mathrm{TiO}_{2}$ was treated in an Ar atmosphere at $700{ }^{\circ} \mathrm{C}$ for $1 \mathrm{~h} .{ }^{35}$ Upon the exposure of $\mathrm{r}-\mathrm{TiO}_{2}$ to water vapor at $130{ }^{\circ} \mathrm{C}$ for $1 \mathrm{~h}$, a hydroxylated surface can be obtained. At this temperature, the molecular water should be desorbed. ${ }^{36}$ On the other hand, oxidized $\mathrm{TiO}_{2}$ was prepared by exposing $\mathrm{r}$ $\mathrm{TiO}_{2}$ to $\mathrm{O}_{2}$ at room temperature. X-ray diffraction (XRD) results (Fig. 1A and Table $\mathrm{S} 1 \dagger$ ) show the same peak position and peak shape over the different $\mathrm{TiO}_{2}$ supports, indicating that their bulk structures are the same. Additionally, the $\mathrm{E}_{\mathrm{g}}$ peak and full width at half maximum (FWHM) in visible Raman spectra (Fig. 1B and Table $\mathrm{S} 2 \dagger$ ) do not change after the hydroxylation and oxidation of reduced $\mathrm{TiO}_{2}$, which also indicates that the bulk states of the different $\mathrm{TiO}_{2}$ samples should be the same. ${ }^{37,38}$

To understand the surface states of $\mathrm{TiO}_{2}$, X-ray photoelectron spectroscopy (XPS) was carried out (Fig. 1C). The binding energy (BE) of XPS Ti $2 \mathrm{p}_{3 / 2}$ on hydroxylated and oxidized surfaces is $459.3 \mathrm{eV}$, which can be assigned to $\mathrm{Ti}^{4+} \cdot{ }^{\mathbf{3 9 , 4 0}}$ Over reduced $\mathrm{TiO}_{2}$, a small shoulder peak at a lower BE of $457.5 \mathrm{eV}$ is observed, which indicates the presence of the $\mathrm{Ti}^{3+}$ state on the reduced surface. ${ }^{39,40}$ When $\mathrm{r}^{-} \mathrm{TiO}_{2}$ was exposed to water vapor, a small shoulder peak at a higher BE of the O 1s peak appears (Fig.$\mathrm{S} 2 \mathrm{~A}_{\dagger}^{\dagger}$ ), suggesting the formation of surface hydroxyl groups via $\mathrm{H}_{2} \mathrm{O}$ dissociation at oxygen vacancies. ${ }^{41}$ Upon the exposure of $\mathrm{r}$ $\mathrm{TiO}_{2}$ to $\mathrm{O}_{2}$, the oxygen vacancies should be filled and oxygen adatoms will be generated on the top of regular $\mathrm{Ti}_{5 \mathrm{c}}$ sites (Fig. S2B $\dagger$ ). The dissociation mechanism of $\mathrm{O}_{2}$ on $\mathrm{TiO}_{2}$ was clarified in previous investigations. ${ }^{42-44}$ The disappearance of the XPS $\mathrm{Ti}^{3+}$ peak on $\mathrm{h}-\mathrm{TiO}_{2}$ and $\mathrm{o}-\mathrm{TiO}_{2}$ further indicates that the dissociative adsorption of water and $\mathrm{O}_{2}$ can occur at oxygen vacancies.

\section{Preparation of $\mathrm{Pt} / \mathrm{TiO}_{2}$ catalysts}

To prepare Pt catalysts on different supports, the pre-treated $\mathrm{TiO}_{2}$ was transferred into a glove box filled with $\mathrm{Ar}$, and thus the surface states of pre-treated $\mathrm{TiO}_{2}$ will remain unchanged. In order to exclude the influence of $\mathrm{O}_{2}$, water and other contaminants in air during the preparation process, $\mathrm{Pt} / \mathrm{TiO}_{2}$ catalysts were also synthesized in a glove box under the protection of an Ar atmosphere.

The influence of surface states of $\mathrm{TiO}_{2}$ on the dispersion of $\mathrm{Pt}$ catalysts was determined by chemisorption, high-angle annular dark-field scanning transmission electron microscopy (HAADFSTEM) and XPS measurements. The $\mathrm{CO}$ chemisorption and $\mathrm{H}_{2}-$ $\mathrm{O}_{2}$ titration results suggest that the dispersion of Pt catalysts is highest on $\mathrm{r}-\mathrm{TiO}_{2}$, followed by $\mathrm{Pt} / \mathrm{h}-\mathrm{TiO}_{2}$ and $\mathrm{Pt} / \mathrm{o}-\mathrm{TiO}_{2}$ (Tables 1 and $\mathrm{S} 3 \dagger$ ). From HAADF-STEM studies (Fig. 2), it was found that the Pt nanoparticles on $\mathrm{r}^{-\mathrm{TiO}_{2}}$ present uniform size distribution with an average diameter of $1.19 \mathrm{~nm}$. In contrast, larger Pt nanoparticles are observed on $\mathrm{h}-\mathrm{TiO}_{2}(1.56 \mathrm{~nm})$ and o- $-\mathrm{TiO}_{2}(1.61$ $\mathrm{nm})$. For the size distribution of catalysts after reaction $(1.46 \pm$ $0.36 \mathrm{~nm}, 1.46 \pm 0.39 \mathrm{~nm}$ and $1.61 \pm 0.43 \mathrm{~nm}$ for $\mathrm{Pt} / \mathrm{r}-\mathrm{TiO}_{2}, \mathrm{Pt} / \mathrm{h}-$ $\mathrm{TiO}_{2}$ and $\mathrm{Pt} / \mathrm{o}-\mathrm{TiO}_{2}$, respectively), only a small variation of particle size can be observed. From XPS investigations (Table
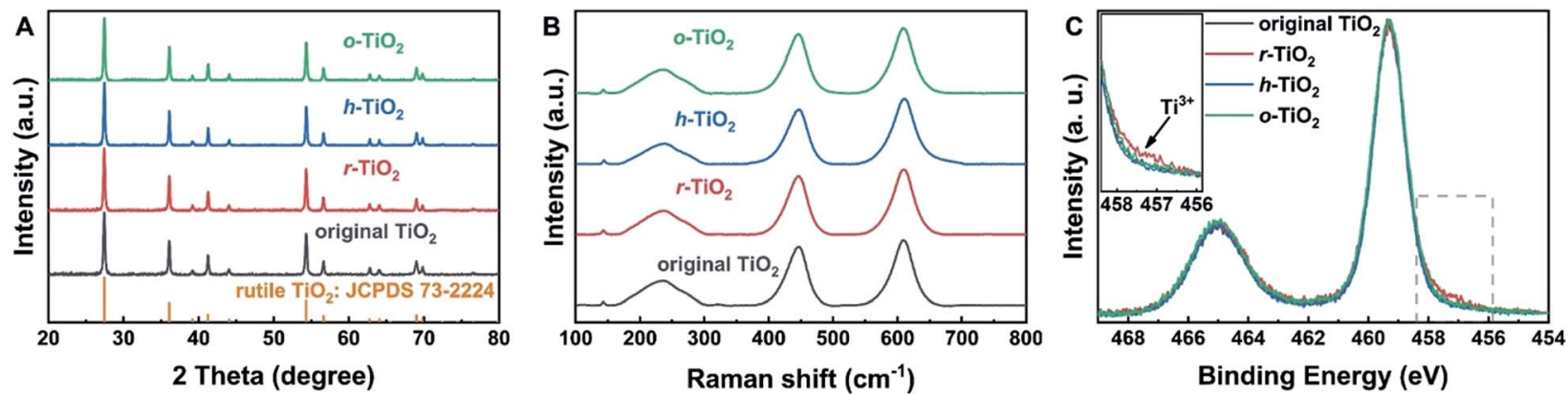

Fig. 1 Bulk and surface properties of $\mathrm{TiO}_{2}$ supports. (A) XRD patterns of different $\mathrm{TiO}_{2}$ supports; (B) Raman spectra of different $\mathrm{TiO} \mathrm{O}_{2}$ supports; (C) XPS Ti $2 p$ peaks of different $\mathrm{TiO}_{2}$ supports. The inset in (C) shows the $\mathrm{Ti}^{3+}$ species on reduced $\mathrm{TiO}_{2}$. 
Table 1 Catalytic properties of different catalysts

\begin{tabular}{lllrr}
\hline Sample & Dispersion $^{a}$ & Specific rate $\times 100^{b}(\mathrm{~mol} \mathrm{CO} /(\mathrm{g}$ Pt $\cdot \mathrm{h}))$ & $\mathrm{TOF}_{\mathrm{a}} \times 100^{c}\left(\mathrm{~s}^{-1}\right)$ & $\mathrm{TOF}_{\mathrm{b}} \times 100^{d}\left(\mathrm{~s}^{-1}\right)$ \\
\hline $\mathrm{Pt} / \mathrm{r}-\mathrm{TiO}_{2}$ & $86 \%$ & 226 & 14.2 & 200.2 \\
$\mathrm{Pt} / \mathrm{h}-\mathrm{TiO}_{2}$ & $53 \%$ & 81 & 8.2 & 187.0 \\
$\mathrm{Pt} / \mathrm{o}-\mathrm{TiO}_{2}$ & $36 \%$ & 8 & 1.3 & 42.6
\end{tabular}

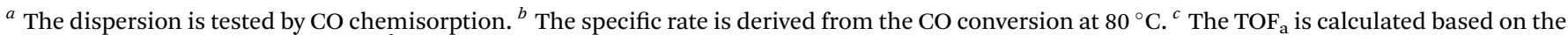
dispersion of metal nanoparticles. ${ }^{d}$ The $\mathrm{TOF}_{\mathrm{b}}$ is calculated based on the length of the perimeter between $\mathrm{Pt}^{c}$ nanoparticles and $\mathrm{TiO}_{2}$.

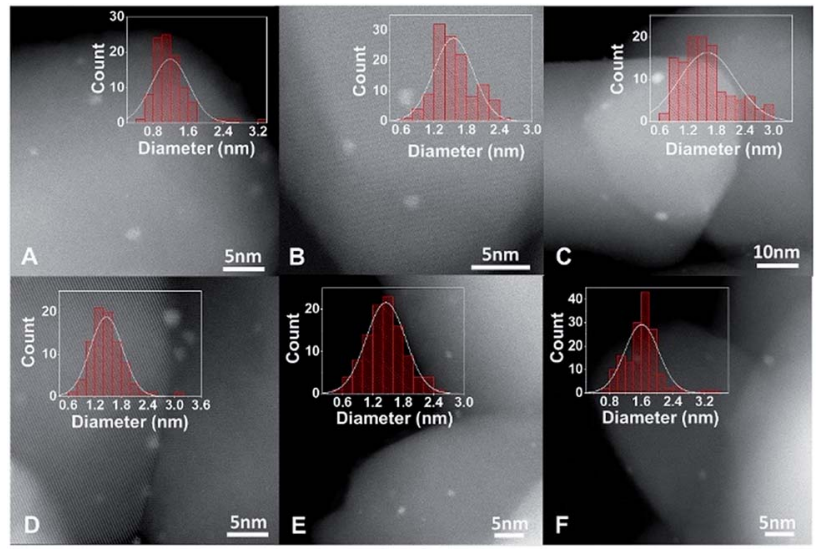

Fig. 2 HAADF-STEM and size distribution of $\mathrm{Pt} / \mathrm{TiO} \mathrm{O}_{2}$ catalysts. (A-C) and (D-F) are HADDF-STEM and size distribution of $\mathrm{Pt} / \mathrm{r}-\mathrm{TiO}_{2}, \mathrm{Pt} / \mathrm{h}-$ $\mathrm{TiO}_{2}$ and $\mathrm{Pt} / \mathrm{O}-\mathrm{TiO}_{2}$ before and after reaction, respectively.

$\mathrm{S} 4 \dagger$ ), it was found that the $\mathrm{Pt} / \mathrm{r}-\mathrm{TiO}_{2}$ catalyst shows a stronger normalized peak area of $\mathrm{Pt} 4 \mathrm{f} / \mathrm{Ti} 2 \mathrm{p}$ than $\mathrm{Pt} / \mathrm{h}-\mathrm{TiO}_{2}$ and $\mathrm{Pt} / \mathrm{o}-$ $\mathrm{TiO}_{2}$, indicating that the $\mathrm{Pt}$ nanoparticles are more highly dispersed on $\mathrm{r}-\mathrm{TiO}_{2}$. The results from $\mathrm{H}_{2}-\mathrm{O}_{2}$ titration, $\mathrm{CO}$ chemisorption, HAADF-STEM and XPS are well consistent with each other, which illustrates that the dispersion of Pt catalysts increases in the sequence of $\mathrm{Pt} / \mathrm{o}-\mathrm{TiO}_{2}<\mathrm{Pt} / \mathrm{h}-\mathrm{TiO}_{2}<\mathrm{Pt} / \mathrm{r}-\mathrm{TiO}_{2}$.

\section{Catalytic performance}

The reactivity to CO oxidation was comparatively studied over the different catalysts (Fig. 3A). Not surprisingly, the best reactivity is observed on $\mathrm{Pt} / \mathrm{r}-\mathrm{TiO}_{2}$. With this catalyst, $50 \% \mathrm{CO}$ conversion takes place at $87.6{ }^{\circ} \mathrm{C}$. In contrast, the $\mathrm{Pt} / \mathrm{h}-\mathrm{TiO}_{2}$ and $\mathrm{Pt} / \mathrm{o}-\mathrm{TiO}_{2}$ catalysts exhibit worse performance, in which $50 \% \mathrm{CO}$ conversion occurs at 102.3 and $126.3{ }^{\circ} \mathrm{C}$, respectively. It is noteworthy that a similar trend of $\mathrm{CO}$ oxidation reactivity can be observed over the catalysts with different concentrations of surface defects, which are prepared through different treatment times (Fig. S3 and $\mathrm{S} 4 \dagger$ ).

The kinetic measurement of CO oxidation was further conducted. It can be found that the specific rate of $\mathrm{Pt} / \mathrm{r}-\mathrm{TiO}_{2}$ to $\mathrm{CO}$ oxidation is $\sim 2.8$ and $\sim 28$ times higher than that of $\mathrm{Pt} / \mathrm{h}-\mathrm{TiO}_{2}$ and $\mathrm{Pt} / \mathrm{o}-\mathrm{TiO}_{2}$, respectively (Table 1). In addition, the turnover frequency (TOF) values based on the surface area $\left(\mathrm{TOF}_{\mathrm{a}}\right)$ and the perimeter length of $\mathrm{Pt}$ nanoparticles $\left(\mathrm{TOF}_{\mathrm{b}}\right)$ are shown in Tables 1 and $\mathrm{S} 3 . \dagger$ The $\mathrm{Pt} / \mathrm{r}-\mathrm{TiO}_{2}$ catalyst shows a $\mathrm{TOF}_{\mathrm{a}}$ of $0.142 \mathrm{~s}^{-1}$ and a $\mathrm{TOF}_{\mathrm{b}}$ of $2.002 \mathrm{~s}^{-1}$, while the $\mathrm{Pt} / \mathrm{h}-\mathrm{TiO}_{2}$ and $\mathrm{Pt} / \mathrm{o}-\mathrm{TiO}_{2}$ catalysts exhibit much lower values. For the $\mathrm{CO}$ oxidation reaction occurring over noble metal catalysts, many previous studies suggested that the reaction obeys the Mars-van Krevelen (M-vK) mechanism on reducible catalysts or the Langmuir-Hinshelwood $(\mathrm{L}-\mathrm{H})$ mechanism on non-reducible catalysts. ${ }^{30,45-47}$ The reaction order test shows that the orders of $\mathrm{CO}$ and $\mathrm{O}_{2}$ on different catalysts are almost the same, negative for $\mathrm{CO}$ and near to zero for $\mathrm{O}_{2}$ (Fig. S5 $\dagger$ ), which is consistent with the $\mathrm{M}-\mathrm{vK}$ mechanism. Furthermore, the comparable apparent activation energy $\left(E_{\mathrm{a}}\right)$ derived from the Arrhenius plot demonstrates that the CO oxidation on the different catalysts should follow the same reaction mechanism (Fig. 3B).

\section{Electronic metal-support interactions}

It has been generally agreed that supported Pt catalysts show low structure sensitivity for CO oxidation. For example, Iglesia and $\mathrm{Lu}$ et al. suggested that the catalytic properties of $\mathrm{Pt} / \mathrm{Al}_{2} \mathrm{O}_{3}$ and $\mathrm{Pt} / \mathrm{TiO}_{2}$ catalysts for $\mathrm{CO}$ oxidation are independent of $\mathrm{Pt}$ cluster size. ${ }^{30,47}$ Although theoretical calculations and surface
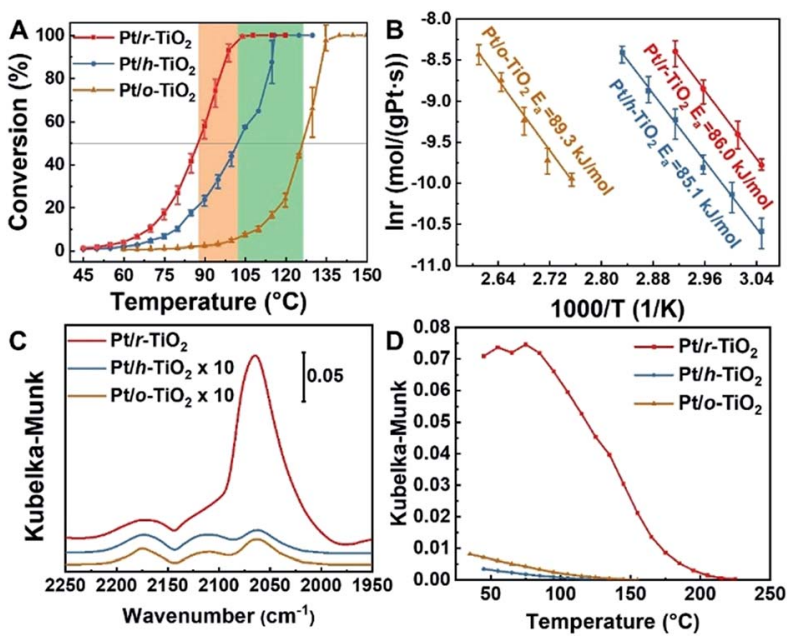

Fig. 3 Reactivity, kinetic properties and DRIFTS of $\mathrm{CO}$ adsorption on $\mathrm{Pt} / \mathrm{TiO}_{2}$ catalysts. (A) Light-off curves of $\mathrm{CO}$ conversion on different catalysts. The $\mathrm{CO}$ oxidation was conducted with a gas composition of $1 \% \mathrm{CO}, 20 \% \mathrm{O}_{2}$ and He balanced, keeping GHSV at $18000 \mathrm{ml} \mathrm{g}_{\mathrm{cat}}{ }^{-1}$ $\mathrm{h}^{-1}$. Each point is tested at a fixed temperature three times and then ramped to higher temperature. (B) Arrhenius plot of $\mathrm{CO}$ oxidation on different catalysts. (C) DRIFTS in CO oxidation ( $1 \% \mathrm{CO}, 20 \% \mathrm{O}_{2}$ and $\mathrm{He}$ balanced) at $80{ }^{\circ} \mathrm{C}$. The spectra were acquired after 5 minutes of reaction. (D) Plot of $\mathrm{CO}$ adsorption amount as a function of temperature in an $\mathrm{Ar}$ atmosphere. $\mathrm{CO}$ was pre-adsorbed at room temperature. 
science experiments suggested that the reaction should be highly structure sensitive, ${ }^{\mathbf{4 8 - 5 0}}$ Christopher et al. showed that CO-induced structure reconstruction of Pt nanoparticles mitigates the inherent structure sensitivity. ${ }^{51}$ Therefore, the observed reactivity difference of $\mathrm{Pt} / \mathrm{TiO}_{2}$ catalysts can be attributed to the different electronic metal-support interactions.

From XPS studies of nano-sized materials, it was found that the final state effect will make BE shift to a higher position for smaller metal nanoparticles. ${ }^{52-54}$ Although the size of Pt nanoparticles on $\mathrm{r}-\mathrm{TiO}_{2}$ is smaller than that on $\mathrm{h}-\mathrm{TiO}_{2}$ and $\mathrm{o}-\mathrm{TiO}_{2}$, the BE of XPS Pt $4 \mathrm{f}_{7 / 2}$ peaks from $\mathrm{Pt} / \mathrm{r}-\mathrm{TiO}_{2}$ is even $\sim 0.2 \mathrm{eV}$ lower than that from $\mathrm{Pt} / \mathrm{h}-\mathrm{TiO}_{2}$ (Fig. S6, S7 and Table S4 $\dagger$ ). This indicates that $\mathrm{Pt}$ may accept more electrons from $\mathrm{r}-\mathrm{TiO}_{2}$ or transfer fewer electrons to $\mathrm{r}-\mathrm{TiO}_{2}$ compared to $\mathrm{Pt} / \mathrm{h}-\mathrm{TiO}_{2}$ and $\mathrm{Pt} /$ o- $\mathrm{TiO}_{2}$ catalysts.

Diffuse reflection infrared Fourier transform spectroscopy (DRIFTS) of CO adsorption was also conducted to demonstrate the electronic metal-support interactions. It can be found that the better catalyst for $\mathrm{CO}$ oxidation shows a larger amount of $\mathrm{CO}$ adsorption in Kubelka-Munk units, which are assumed to be linearly related to the adsorbate coverage (Fig. 3C). ${ }^{\mathbf{4} 55}$ Besides the larger $\mathrm{CO}$ adsorption amount, the $\mathrm{Pt} / \mathrm{r}-\mathrm{TiO}_{2}$ catalyst also presents $\sim 80{ }^{\circ} \mathrm{C}$ higher temperature for complete CO desorption compared to $\mathrm{Pt} / \mathrm{h}-\mathrm{TiO}_{2}$ and $\mathrm{Pt} / \mathrm{o}-\mathrm{TiO}_{2}$, which indicates that $\mathrm{CO}$ binds stronger with $\mathrm{Pt} / \mathrm{r}-\mathrm{TiO}_{2}$ (Fig. 3D). The higher $\mathrm{CO}$ coverage induced by electronic interactions should be detrimental to the reactivity of $\mathrm{Pt} / \mathrm{r}-\mathrm{TiO}_{2}$ in kinetic aspects due to the negative reaction order. However, $\mathrm{Pt} / \mathrm{r}-\mathrm{TiO}_{2}$ shows better reactivity than $\mathrm{Pt} / \mathrm{h}-\mathrm{TiO}_{2}$ and $\mathrm{Pt} / \mathrm{o}-\mathrm{TiO}_{2}$. Therefore, it can be drawn that electronic interactions play a dominant role thermodynamically in reactivity modulation which is demonstrated by the DFT calculations.

\section{Theoretical calculations}

Density functional theory (DFT) calculations provide further insights into the electronic interactions between metals and supports, and their influence on catalytic reactivity. Bader charge analysis shows that the average charges of Pt on $\mathrm{r}-\mathrm{TiO}_{2}$, $\mathrm{h}-\mathrm{TiO}_{2}$ and $\mathrm{o}-\mathrm{TiO}_{2}$ are determined to be $+0.04,+0.08$ and +0.10 , respectively (Fig. S8 $\dagger$ ), which agrees with XPS measurements.

The CO adsorbed at the interface of $\mathrm{Pt} / \mathrm{r}-\mathrm{TiO}_{2}$ is found to have a binding energy of $2.08 \mathrm{eV}$, which is 0.29 and $0.21 \mathrm{eV}$ higher than those for the CO adsorbed at the interface of $\mathrm{Pt} / \mathrm{h}$ $\mathrm{TiO}_{2}$ and $\mathrm{Pt} / \mathrm{O}-\mathrm{TiO}_{2}$, respectively. This result is well consistent with the DRIFTS results. Furthermore, the reaction barriers of adsorbed $\mathrm{CO}$ with the lattice oxygen of $\mathrm{TiO}_{2}(\mathrm{CO}+\mathrm{O})$ were also calculated. Fig. 4 shows the energy barriers and TS geometries for CO oxidation on the different catalysts. It can be found that the energy barriers for the $\mathrm{CO}$ reaction are $0.89 \mathrm{eV}, 0.96 \mathrm{eV}$ and $1.04 \mathrm{eV}$ on $\mathrm{Pt} / \mathrm{r}-\mathrm{TiO}_{2}, \mathrm{Pt} / \mathrm{h}-\mathrm{TiO}_{2}$ and $\mathrm{Pt} / \mathrm{o}-\mathrm{TiO}_{2}$, respectively. The barrier is consistent with $E_{\mathrm{a}}$ derived from the kinetic test $(\sim 0.95$ $\mathrm{eV}$. However, compared with the reaction path on $\mathrm{Pt} / \mathrm{h}-\mathrm{TiO}_{2}$ and $\mathrm{Pt} / \mathrm{o}-\mathrm{TiO}_{2}$, the route on $\mathrm{Pt} / \mathrm{r}-\mathrm{TiO}_{2}$ is energetically more favorable which is downhill for further $\mathrm{CO}_{2}$ desorption and the free energy barrier of the CO oxidation process is also slightly

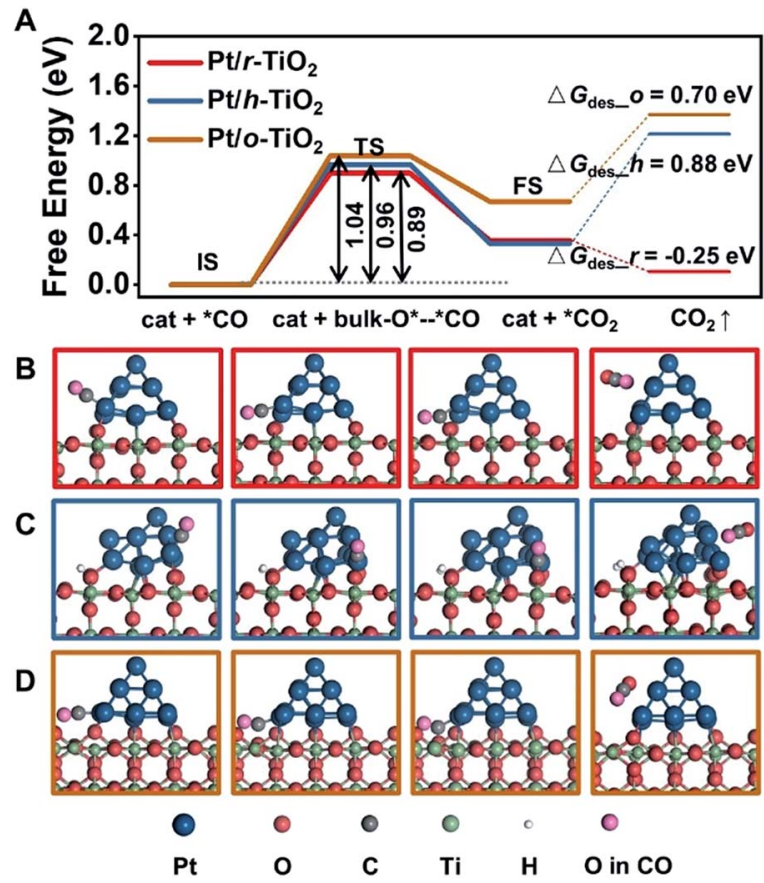

Fig. 4 Calculated $\mathrm{CO}$ oxidation over $\mathrm{Pt} / \mathrm{TiO}_{2}$ catalysts. (A) Free energy barriers for $\mathrm{CO}$ oxidation. (B-D) Models from left to right represent the initial state (IS), transition state (TS), final state (FS) and $\mathrm{CO}_{2}$ desorption of $\mathrm{CO}$ oxidation on $\mathrm{Pt} / \mathrm{r}-\mathrm{TiO}_{2}, \mathrm{Pt} / \mathrm{h}-\mathrm{TiO}_{2}$ and $\mathrm{Pt} / \mathrm{o}-\mathrm{TiO}_{2}$, respectively.

favored. This indicates that $\mathrm{Pt} / \mathrm{r}-\mathrm{TiO}_{2}$ should exhibit better reactivity for $\mathrm{CO}$ oxidation than $\mathrm{Pt} / \mathrm{h}-\mathrm{TiO}_{2}$ and $\mathrm{Pt} / \mathrm{o}-\mathrm{TiO}_{2}$. Subsequently, the reaction barriers for $\mathrm{CO}$ oxidation on different $\mathrm{Pt} / \mathrm{TiO}_{2}$ surfaces with oxygen vacancies $\left(\mathrm{CO}+\mathrm{O}_{2}+\right.$ O_vac) were calculated (Fig. S9†). It can be seen that the reaction barriers for $\mathrm{CO}+\mathrm{O}_{2}+\mathrm{O} \_$vac are much lower than those for $\mathrm{CO}+$ $\mathrm{O}$ over different catalysts.

\section{Conclusions}

Although it has been known that the surface states of supports should play an important role in the catalytic properties of catalysts, an understanding of the correlation between the surface states of supports and catalytic performance is still lacking, especially for real supported catalytic systems. Surface science investigations have shown that metal nanoparticles can be trapped at $\mathrm{O}$ adatoms and $\mathrm{O}$ vacancies on the $\mathrm{TiO}_{2}$ (110) surface under ultra-high vacuum conditions. ${ }^{13-15,22}$ However, in practice, the influence of air atmosphere and the structural complexity has made direct studies of real supported catalysts very difficult. In the present study, the preparation of different catalysts was carried out under the protection of an $\mathrm{Ar}$ atmosphere, and thus the influence of active molecules $\left(\mathrm{O}_{2}, \mathrm{H}_{2} \mathrm{O}\right.$, etc.) in air can be excluded, but this was often ignored before.

In summary, we demonstrate how sensitively the catalytic performance of Pt catalysts depends on the surface states of $\mathrm{TiO}_{2}$ supports. Before depositing Pt catalysts, different $\mathrm{TiO}_{2}$ supports, including reduced, hydroxylated and oxidized types, were obtained via pre-treatments in different atmospheres. The 
highest reactivity for $\mathrm{CO}$ oxidation was achieved using Pt catalysts supported on $\mathrm{r}-\mathrm{TiO}_{2}$, whereas worse performance was seen for the catalysts supported on $\mathrm{h}-\mathrm{TiO}_{2}$ and $\mathrm{o}-\mathrm{TiO}_{2}$. The established surface state-electronic structure-reactivity relationship clearly illustrates the important role of surface defects in catalytic performance and can be readily extended to many other metal/oxide catalytic systems.

\section{Conflicts of interest}

There are no conflicts to declare.

\section{Acknowledgements}

This work was financially supported by the National Key Research and Development Program of China (No. 2016YFB0600901), the National Science Foundation of China (No. 21525626, 91645106, and 21603159) and the Program of Introducing Talents of Discipline to Universities (No. B06006). We thank Jie Xu and Prof. Jun Luo from Tianjin University of Technology for HADDF-STEM characterization and Chao Wang from Dalian Institute of Chemical Physics for XPS characterization. We also thank Hao Li from Tianjin University, and Dr Lijun Gao and Dr Jinhu Dong from Dalian Institute of Chemical Physics for fruitful discussions.

\section{References}

1 M. Ahmadi, H. Mistry and B. Roldan Cuenya, J. Phys. Chem. Lett., 2016, 7, 3519-3533.

2 F. Shi, L. R. Baker, A. Hervier, G. A. Somorjai and K. Komvopoulos, Nano Lett., 2013, 13, 4469-4474.

3 N. J. Divins, I. Angurell, C. Escudero, V. Pérez-Dieste and J. Llorca, Science, 2014, 346, 620-623.

4 Y. Wang, D. Widmann and R. J. Behm, ACS Catal., 2017, 7, 2339-2345.

5 Y. Wang, D. Widmann, M. Heenemann, T. Diemant, J. Biskupek, R. Schlögl and R. J. Behm, J. Catal., 2017, 354, 46-60.

6 K. Ding, A. Gulec, A. M. Johnson, N. M. Schweitzer, G. D. Stucky, L. D. Marks and P. C. Stair, Science, 2015, 350, 189-192.

7 M. Moses-DeBusk, M. Yoon, L. F. Allard, D. R. Mullins, Z. Wu, X. Yang, G. Veith, G. M. Stocks and C. K. Narula, J. Am. Chem. Soc., 2013, 135, 12634-12645.

8 L. Nie, D. Mei, H. Xiong, B. Peng, Z. Ren, X. I. P. Hernandez, A. DeLaRiva, M. Wang, M. H. Engelhard, L. Kovarik, A. K. Datye and Y. Wang, Science, 2017, 358, 1419-1423.

9 D. A. J. M. Ligthart, R. A. van Santen and E. J. M. Hensen, Angew. Chem., Int. Ed., 2011, 50, 5306-5310.

10 H. Li, S. Zha, Z.-J. Zhao, H. Tian, S. Chen, Z. Gong, W. Cai, Y. Wang, Y. Cui, L. Zeng, R. Mu and J. Gong, ACS Catal., 2018, 8, 5526-5532.

11 B. Qiao, A. Wang, X. Yang, L. F. Allard, Z. Jiang, Y. Cui, J. Liu, J. Li and T. Zhang, Nat. Chem., 2011, 3, 634-641.

12 Y. Lou and J. Liu, Ind. Eng. Chem. Res., 2017, 56, 6916-6925.
13 D. Matthey, J. G. Wang, S. Wendt, J. Matthiesen, R. Schaub, E. Lægsgaard, B. Hammer and F. Besenbacher, Science, 2007, 315, 1692-1696.

14 J. Ø. Hansen, E. Lira, P. Galliker, J.-G. Wang, P. T. Sprunger, Z. Li, E. Lægsgaard, S. Wendt, B. Hammer and F. Besenbacher, J. Phys. Chem. C, 2010, 114, 16964-16972.

15 F. Rieboldt, L. B. Vilhelmsen, S. Koust, J. V. Lauritsen, S. Helveg, L. Lammich, F. Besenbacher, B. Hammer and S. Wendt, J. Chem. Phys., 2014, 141, 214702.

16 S. Bonanni, K. Aït-Mansour, W. Harbich and H. Brune, J. Am. Chem. Soc., 2012, 134, 3445-3450.

17 H.-Z. Cui, Y. Guo, X. Wang, C.-J. Jia and R. Si, Catalysts, 2016, 6, 37.

18 J. Wan, W. Chen, C. Jia, L. Zheng, J. Dong, X. Zheng, Y. Wang, W. Yan, C. Chen, Q. Peng, D. Wang and Y. Li, Adv. Mater., 2018, 30, 1705369.

19 L. DeRita, J. Resasco, S. Dai, A. Boubnov, H. V. Thang, A. S. Hoffman, I. Ro, G. W. Graham, S. R. Bare, G. Pacchioni, X. Pan and P. Christopher, Nat. Mater., 2019, 18, 746-751.

20 E. C. H. Sykes, Nat. Mater., 2019, 18, 663-664.

21 X. Jiao, Z. Chen, X. Li, Y. Sun, S. Gao, W. Yan, C. Wang, Q. Zhang, Y. Lin, Y. Luo and Y. Xie, J. Am. Chem. Soc., 2017, 139, 7586-7594.

22 A. Mellor, D. Humphrey, C. M. Yim, C. L. Pang, H. Idriss and G. Thornton, J. Phys. Chem. C, 2017, 121, 24721-24725.

23 X. Tong, L. Benz, S. Chrétien, H. Metiu, M. T. Bowers and S. K. Buratto, J. Phys. Chem. C, 2010, 114, 3987-3990.

24 O. Bikondoa, C. L. Pang, R. Ithnin, C. A. Muryn, H. Onishi and G. Thornton, Nat. Mater., 2006, 5, 189-192.

25 S. Wendt, J. Matthiesen, R. Schaub, E. K. Vestergaard, E. Lægsgaard, F. Besenbacher and B. Hammer, Phys. Rev. Lett., 2006, 96, 066107.

26 R. Mu, D. C. Cantu, X. Lin, V.-A. Glezakou, Z. Wang, I. Lyubinetsky, R. Rousseau and Z. Dohnálek, J. Phys. Chem. Lett., 2014, 5, 3445-3450.

27 R. Mu, D. C. Cantu, V.-A. Glezakou, I. Lyubinetsky, R. Rousseau and Z. Dohnálek, J. Phys. Chem. C, 2015, 119, 23552-23558.

28 Z.-T. Wang, Y.-G. Wang, R. Mu, Y. Yoon, A. Dahal, G. K. Schenter, V.-A. Glezakou, R. Rousseau, I. Lyubinetsky and Z. Dohnálek, Proc. Natl. Acad. Sci. U. S. A., 2017, 114, 1801-1805.

29 R. Mu, Z.-j. Zhao, Z. Dohnalek and J. Gong, Chem. Soc. Rev., 2017, 46, 1785-1806.

30 N. Li, Q.-Y. Chen, L.-F. Luo, W.-X. Huang, M.-F. Luo, G.-S. Hu and J.-Q. Lu, Appl. Catal., B, 2013, 142-143, 523-532.

31 G. T. K. K. Gunasooriya, E. G. Seebauer and M. Saeys, ACS Catal., 2017, 7, 1966-1970.

32 M. Ni, M. K. H. Leung, D. Y. C. Leung and K. Sumathy, Renewable Sustainable Energy Rev., 2007, 11, 401-425.

33 J. Yu, L. Qi and M. Jaroniec, J. Phys. Chem. C, 2010, 114, 13118-13125.

34 S. Xie, Y. Wang, Q. Zhang, W. Deng and Y. Wang, ACS Catal., 2014, 4, 3644-3653.

35 S. Wendt, R. Schaub, J. Matthiesen, E. K. Vestergaard, E. Wahlström, M. D. Rasmussen, P. Thostrup, 
L. M. Molina, E. Lægsgaard, I. Stensgaard, B. Hammer and F. Besenbacher, Surf. Sci., 2005, 598, 226-245.

36 J. Ø. Hansen, J. Matthiesen, E. Lira, L. Lammich and S. Wendt, Surf. Sci., 2017, 666, 113-122.

37 J. C. Parker and R. W. Siegel, Appl. Phys. Lett., 1990, 57, 943945.

38 H. Zhang, J. Cai, Y. Wang, M. Wu, M. Meng, Y. Tian, X. Li, J. Zhang, L. Zheng, Z. Jiang and J. Gong, Appl. Catal., B, 2018, 220, 126-136.

39 A. N. Shultz, W. Jang, W. M. Hetherington, D. R. Baer, L.-Q. Wang and M. H. Engelhard, Surf. Sci., 1995, 339, 114124.

40 F. Guillemot, M. C. Porté, C. Labrugère and C. Baquey, J. Colloid Interface Sci., 2002, 255, 75-78.

41 J. Balajka, M. A. Hines, W. J. I. DeBenedetti, M. Komora, J. Pavelec, M. Schmid and U. Diebold, Science, 2018, 361, 786-789.

42 Y. Du, Z. Dohnálek and I. Lyubinetsky, J. Phys. Chem. C, 2008, 112, 2649-2653.

43 Z.-T. Wang, Y. Du, Z. Dohnálek and I. Lyubinetsky, J. Phys. Chem. Lett., 2010, 1, 3524-3529.

44 E. Lira, J. Ø. Hansen, P. Huo, R. Bechstein, P. Galliker, E. Lægsgaard, B. Hammer, S. Wendt and F. Besenbacher, Surf. Sci., 2010, 604, 1945-1960.

45 S. T. Daniells, A. R. Overweg, M. Makkee and J. A. Moulijn, J. Catal., 2005, 230, 52-65.
46 M. Kotobuki, R. Leppelt, D. A. Hansgen, D. Widmann and R. J. Behm, J. Catal., 2009, 264, 67-76.

47 A. D. Allian, K. Takanabe, K. L. Fujdala, X. Hao, T. J. Truex, J. Cai, C. Buda, M. Neurock and E. Iglesia, J. Am. Chem. Soc., 2011, 133, 4498-4517.

48 T. Jiang, D. J. Mowbray, S. Dobrin, H. Falsig, B. Hvolbæk, T. Bligaard and J. K. Nørskov, J. Phys. Chem. C, 2009, 113, 10548-10553.

49 S. Bonanni, K. Aït-Mansour, W. Harbich and H. Brune, J. Am. Chem. Soc., 2014, 136, 8702-8707.

50 O. Balmes, G. Prevot, X. Torrelles, E. Lundgren and S. Ferrer, ACS Catal., 2016, 6, 1285-1291.

51 M. J. Kale and P. Christopher, ACS Catal., 2016, 6, 55995609.

52 M. Turner, V. B. Golovko, O. P. H. Vaughan, P. Abdulkin, A. Berenguer-Murcia, M. S. Tikhov, B. F. G. Johnson and R. M. Lambert, Nature, 2008, 454, 981.

53 D. P. Anderson, J. F. Alvino, A. Gentleman, H. A. Qahtani, L. Thomsen, M. I. J. Polson, G. F. Metha, V. B. Golovko and G. G. Andersson, Phys. Chem. Chem. Phys., 2013, 15, 3917-3929.

54 W. E. Kaden, T. Wu, W. A. Kunkel and S. L. Anderson, Science, 2009, 326, 826-829.

55 T. Armaroli, T. Bécue and S. Gautier, Oil Gas Sci. Technol., 2004, 59, 215-237. 